\title{
Selective attention to the chemosensory modality
}

\author{
CHARLES SPENCE \\ University of Oxford, Oxford, England \\ BIRGIT KETTENMANN and GERD KOBAL \\ University of Erlangen-Nürnberg, Erlangen, Germany \\ and \\ FRANCIS P. MCGLONE \\ Unilever Research, Port Sunlight Laboratories, Wirral, England \\ and Centre for Cognitive Neuroscience, University of Wales, Bangor, Wales
}

\begin{abstract}
Previous studies have shown that behavioral responses to auditory, visual, and tactile stimuli are modulated by expectancies regarding the likely modality of an upcoming stimulus (see Spence \& Driver, 1997). In the present study, we investigated whether people can also selectively attend to the chemosensory modality (involving responses to olfactory, chemical, and painful stimuli). Participants made speeded spatial discrimination responses (left vs. right) to an unpredictable sequence of odor and tactile targets. Odor stimuli were presented to either the left or the right nostril, embedded in a birhinally applied constant airstream. Tactile stimuli were presented to the left or the right hand. On each trial, a symbolic visual cue predicted the likely modality for the upcoming target (the cue was a valid predictor of the target modality on the majority of trials). Response latencies were faster when targets were presented in the expected modality than when they were presented in the unexpected modality, showing for the first time that behavioral responses to chemosensory stimuli can be modulated by selective attention.
\end{abstract}

Can people selectively direct their attention to a particular sensory modality, and, if so, what are the consequences for the perception of stimuli presented in that modality? This question, which has long been of interest to psychologists (e.g., Hirsch, 1862; see Nicolas, 1997; Wundt, 1893), has typically been addressed with reference to the effects of voluntary (or endogenous) shifts of attention to the auditory, visual, and tactile modalities. The majority of research now supports the claim that attending to one modality can facilitate the perception of stimuli in that modality relative to when attention is directed to another modality (see Spence \& Driver, 1997, and Spence, Nicholls, \& Driver, in press, for reviews). Preferential processing has been demonstrated in terms of both a lowered threshold for the detection of attended stimuli and a facilitation of the latency and/or accuracy of speeded responses to attended versus nonattended stimuli. Considerable clinical interest has been aroused recently regarding the mechanisms by which attention is shifted from one modality to another, following suggestions that certain clinical populations may show selective deficits in their ability to shift attention from one modality to another (e.g., Ciesielski, Knight, Prince, Harris, \& Handmaker, 1995; Godefroy, Lhullier, \& Rousseaux, 1996; Hanewinkel \& Ferstl, 1996).

This research was supported by Unilever Research. Correspondence should be addressed to C. Spence, Department of Experimental Psychology, University of Oxford. South Parks Road. Oxford, OXI 3UD. England (e-mail: charles.spence@psy.ox.ac.uk).
Spence and Driver (1997) reported a study in which normal participants made speeded discrimination responses to an unpredictable sequence of auditory and visual stimuli presented to either the left or the right of fixation. At the beginning of every trial, a symbolic visual cue indicated the likely modality of the upcoming target (this cue was valid on $80 \%$ of trials and invalid on the remaining $20 \%$ of trials). Participants responded more rapidly when the target occurred in the expected modality than when it occurred in the unexpected modality, showing that attention can be selectively directed to audition or vision.

This research has recently been extended to show that people can also selectively attend to the tactile (Spence, Nicholls, \& Driver, in press; see also Whang, Burton, \& Shulman, 1991) and nociceptive (i.e., pain) modalities (Miron, Duncan, \& Bushnell, 1989). Participants in Miron et al.'s study detected changes in the temperature of a thermal diode placed on the cheek more rapidly when attention was directed toward this noxious heat stimulus than when it was directed toward vision (see also McCaul \& Haugtvedt, 1982; see McCaul \& Malott, 1984, for a review). Using the same paradigm, behavioral and neurophysiological studies in monkeys have shown that selective attention to noxious thermal stimuli may modulate performance by increasing the responsiveness of nociceptive neurons in the medullary dorsal horn (Bushnell, Duncan, Dubner, \& He, 1984; Bushnell, Duncan, Dubner, Jones, \& Maixner, 1985; Hayes, Price, Ruda, \& Dubner, 1981) and that selective attention to touch modulates 
activity in the primary and secondary somatosensory cortex (Hsiao, O'Shaughnessy, \& Johnson, 1993).

However, despite this recent interest in the behavioral consequences of attending to a modality and the mechanisms underlying such effects, we are aware of only one study that has attempted to investigate the question of whether attention can also be selectively directed to chemosensation (Krauel, Pause, Sojka, Schott, \& Ferstl, 1998). Participants in Krauel et al.'s study were presented with slow English rock songs and, simultaneously, with a birhinally presented sequence of odors. Participants had either to count the number of times the target word you appeared in the song ("attend audition" condition) or to press a button whenever an "infrequent" odor occurred ("attend olfaction" condition). Analysis of the olfactory event-related potential data showed that the latencies of the chemosensory evoked potential components (N1, P2, $\mathrm{N} 2$ ) were decreased when attention was selectively directed to olfaction rather than audition. Additionally, the amplitude of the late positive components (P3-1, P3-2) also showed attentional modulation. However, although suggestive, these results provide no direct evidence about the perceptual consequences of selectively attending to chemosensation, since no behavioral measures were recorded.

The unique neuroanatomical layout of the olfactory system may have important implications for our ability to selectively attend to olfaction, since it is the only modality in which the sensory receptors do not project to the cortex via the thalamus. Instead, olfactory information bypasses the thalamus via a connection between the pyriform cortex and other cortical structures (see Price, 1990). The importance of this neuroanatomical difference relates to claims that the thalamus may play a crucial role in mediating selective attention to a modality, via thalamic gating (e.g., Bushnell et al., 1985; McCormick \& Bal, 1994; see also Frith \& Friston, 1996). The lack of direct thalamocortical connections may mean that, in contrast to other modalities so far investigated, people are unable to selectively attend to olfaction. ${ }^{1}$

Behavioral support for such a claim comes from studies showing that manual response latencies to olfactory stimuli are particularly slow (e.g., Cain, 1976, 1988; Wells, 1929; though see Kobal, Hummel, \& Van Toller, 1992). For example, Cain (1976) reported average simple detection latencies for odor stimuli of 600-1,200 msec (compare this with average detection latencies of approximately $200 \mathrm{msec}$ for auditory, visual, and tactile stimuli; see Spence \& Driver, 1997). This difference, which is too large to be accounted for solely on the basis of differences in transduction latencies (Cain, 1988; Hummel, Knecht, \& Kobal, 1996), may reflect a relative inability to selectively facilitate the processing of olfactory stimuli through the direction of attention to chemosensation. The unique neuroanatomical architecture of the olfactory system, together with the slow responses to olfactory stimuli, means that it is by no means certain that behav- ioral responses to chemosensory stimuli can be selectively modulated by attention. ${ }^{2}$ We therefore attempted to investigate this question in the present study.

We presented an unpredictable sequence of odor stimuli to either nostril and tactile stimuli to either hand (see Figure 1). Every target was preceded by a symbolic visual cue that correctly predicted the target modality on the majority of trials. Participants were instructed to attend covertly (i.e., in the absence of any shift in the peripheral receptors) to the cued modality and make speeded left versus right discrimination responses to all targets. We used the same spatial discrimination task in both modalities to minimize the effect of task switching on any modality-cuing effects observed (i.e., the possibility that the modality cue might be used by participants as a cue to prepare for a particular task, rather than to prepare for stimuli appearing in a particular modality; see Allport, Styles, \& Hsieh, 1994; Rogers \& Monsell, 1995; Spence \& Driver, 1997). If people can selectively attend to the chemosensory modality, we would expect that response latencies should be faster and/or more accurate when odor targets were preceded by a valid "expect-odor" cue than by an invalid "expect-touch" cue, and vice versa for tactile stimuli. We chose to pair tactile stimuli with chemosensory stimuli in the present study to maximize our chances of finding behavioral effects of the attentional manipulation, since it has recently been shown that the costs associated with shifting attention to/from touch are significantly greater than those associated with shifts to/from audition and vision (Spence, Nicholls, \& Driver, in press).

Although some researchers have argued that "pure" olfactory stimuli presented monorhinally to one nostril or the other can be localized correctly (e.g., Békésy, 1964; Bellas, Novelly, Eskenazi, \& Wasserstein, 1988), others have reported that people cannot discriminate the nostril to which olfactory stimuli are presented unless the stimulant also activates the trigeminal receptors of the chemosensory modality (e.g., Kobal, Van Toller, \& Hummel, 1989; Skramlik, 1925; Van Toller, Kirk-Smith, Sleight, Wood, \& Lombard, 1980; see also Schneider \& Schmidt, 1967). Therefore, in order for participants to be able to localize the odor stimuli accurately in the present study, we used a relatively high-intensity menthol $(21 \mathrm{ppm})$ as the odor stimulus to activate both the olfactory and the trigeminal systems (e.g., Kobal et al., 1992; Kobal et al., 1989; Schneider \& Schmidt, 1967).

\section{METHOD}

\section{Participants}

Nine participants ( 5 naive participants and the 4 authors; 6 men and 3 women) took part in this experiment. All reported normal olfaction and touch. The experimental session lasted $40 \mathrm{~min}$.

\section{Apparatus and Materials}

The participants were seated comfortably in an armchair for the duration of the experiment. An extractor fan was located directly above the participant's head, to ensure that the testing environment 


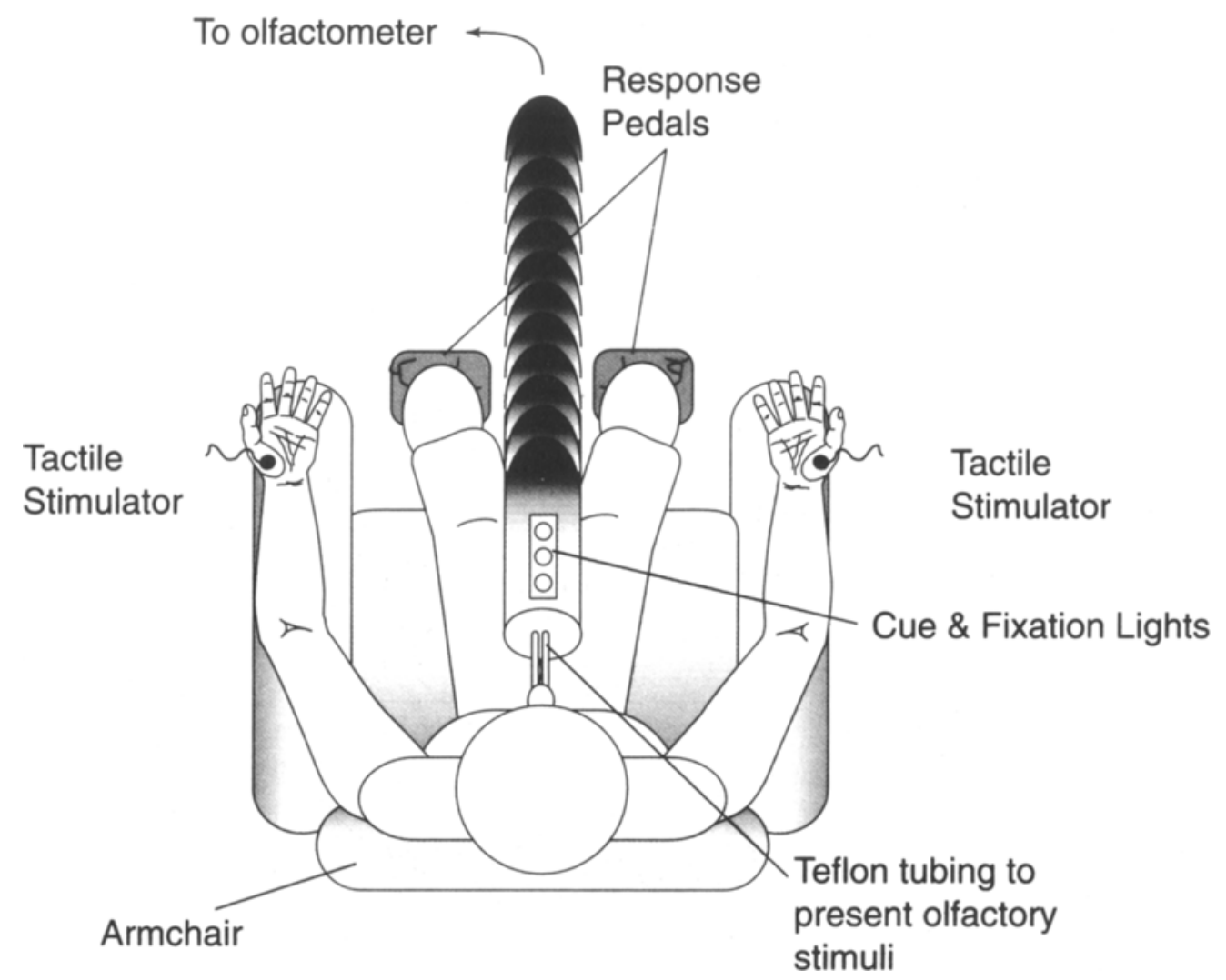

Figure 1. Schematic bird's eye view of the participant sitting in front of the olfactometer. Olfactory target stimuli were presented monorhinally by means of two Teflon tubes, one inserted approximately $1 \mathrm{~cm}$ into each nostril. The positions of the cue and fixation lights, the tactile stimulators, and the response pedals used in this experiment are also shown.

remained free from transitory odors. Odor stimuli were presented by means of a specialized constant-flow olfactometer (see Kobal, 1985; Kobal \& Hummel, 1991) that could present an odor to either nostril (see Figure 1). Using two identical stimulators within the olfactometer, the airstream was led into both nasal cavities by way of Teflon tubing ( $6 \mathrm{~cm}$ long, $4 \mathrm{~mm}$ outer diameter), with a total flow rate of $140 \mathrm{ml} / \mathrm{sec}$. In the olfactometer, the odorless interval current and the carrier current for the odorized air could replace each other without producing mechanical stimulation (see Kobal \& Hummel, 1991, for details). A computer-controlled solenoid valve initiated which current was removed through a vacuum and, hence, to which nostril the odor was presented. Using this birhinal stimulation technique, we could present precisely lateralized stimuli to the nasal mucosa of either the left or the right nostril. Importantly, we were able to do this without providing any other cues to facilitate in the lateralization of the odor stimuli-that is, the stimuli were delivered without altering the mechanical, tactile, or thermal conditions at the stimulated mucosa (see Wells, 1929).

Odor targets consisted of a 500-msec suprathreshold pulse of menthol ( $21 \mathrm{ppm})$ that was introduced into a constant-flow airstream with controlled temperature $\left(36.5^{\circ} \mathrm{C}\right)$ and humidity $(80 \%$ relative humidity). The rise time for olfactory stimulation was below $20 \mathrm{msec}$. No attempt was made to synchronize stimulus presentation with the participant's breathing.

Oticon-A bone-conduction vibrators, with vibrating surfaces of $1.6 \times 2.4 \mathrm{~cm}$, were attached to the thenar emenance (the fleshy part at the base of the thumb) of each of the participant's hands using double-sided tape. The participants rested their arms comfortably by their sides on the armrests of the chair, with their hands upturned. This arrangement ensured a constant contact between the participants' hand and the vibrators throughout the experimental session. Tactile stimuli consisted of the presentation of a white noise signal to the vibrator on either side for $500 \mathrm{msec}$ at approximately $36 \mathrm{~dB}(\mathrm{~A})$. White noise was also presented via headphones throughout the experiment, to mask completely the sound of the vibrotactile stimulators and the operation of the olfactometer. No attempt was made to match the intensity of the tactile and olfactory stimuli, given that there is dispute regarding how, and even whether, this can be achieved (see Spence \& Driver, 1997).

A red light-emitting diode (LED) was used as a fixation point, placed directly in front of the participants' eyes at a distance of approximately $15 \mathrm{~cm}$. The participants were instructed to fixate this light, which was illuminated throughout the experiment. A red LED placed directly above the fixation light, and stencilled with the letters $O L F$, served as the odor cue. Another red LED placed directly below the fixation light, stencilled with the letters $T A C$, served as the tactile cue. The participants were required to depress two footpedals throughout the experiment, one under the toes of each foot. The participants responded by briefly releasing one or the other pedal, lifting their left toe for left targets and their right toe to indicate right targets, irrespective of the target modality.

\section{Design}

The two within-participants factors were target modality (odor or touch) and cue validity (valid or invalid). The participants completed one block of 96 trials. Sixty-four $(67 \%)$ of the trials were 
valid, where the cue correctly predicted the target modality, and 32 $(33 \%)$ were invalid, where the cue predicted the incorrect target modality. An equal number of odor and tactile targets were presented from each side in each modality. The cue validity was the same for both modalities, and olfaction and touch were cued equally often. The various conditions were presented in a random order. Reaction times (RTs) were measured in milliseconds from target onset, using a custom PC-based computer program and interface board that controlled the olfactometer, vibrators, LEDs, and response pedals.

\section{Procedure}

To avoid the respiratory flow of air in the nose, the participants were trained to practice velopharyngeal closure, breathing through the mouth (Kobal, 1985) prior to the commencement of the experimental session. At the start of each trial, the central modality cue was presented for $5,500 \mathrm{msec}$. The target was presented as this cue was extinguished (the participants were informed of this contingency). The two cue lights flickered for $780 \mathrm{msec}$, to provide feedback if participants made an incorrect response, failed to make a response when a target occurred, or else responded prior to the onset of the target.

The participants were told about the cue validities at the beginning of the experiment and were instructed to attend to the modality indicated by the cue as most likely on each trial. The participants were also instructed to make the left/right discrimination response as rapidly and accurately as possible. The trial was terminated if no response was made within $7,500 \mathrm{msec}$ of target onset. The interval between successive targets was $14,000 \mathrm{msec}$ (14,280 $\mathrm{msec}$ following an incorrect response). This interval was chosen to minimize the influence of adaptation of the olfactory or trigeminal systems on target performance (see Hummel et al., 1996; Hummel \& Kobal, 1999).

\section{RESULTS}

Trials on which an incorrect response occurred were discarded from the RT analysis. In addition, trials $(5 \%)$ on which the RT was below $100 \mathrm{msec}$ or over $2,000 \mathrm{msec}$ were also removed. The interparticipant mean RTs (after these exclusions), together with the mean cuing effect (i.e., the difference between RTs for invalid and valid trials), are shown in Table 1. Mean, rather than median, RTs were computed for each participant because the different cue conditions had different probabilities of occurrence (see Miller, 1988), with valid trials being more likely.

The RT data were analyzed using a within-subjects analysis of variance (ANOVA), with the factors of target modality (odor or touch) and cue validity (valid or invalid).

Table 1

Mean Reaction Times (RTs, in Milliseconds), With Standard Errors, and Percentages of Errors for Olfactory and Tactile Targets in the Spatial Discrimination Task of Experiment 1

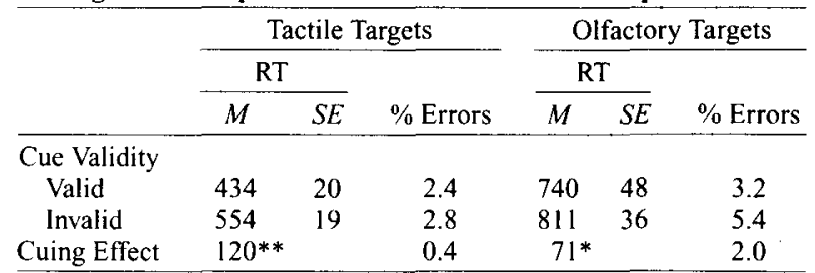

${ }^{*} p<.05, t$-test pairwise comparison. ${ }^{* *} p<.01, t$-test pairwise comparison.
There was a significant main effect of target modality $[F(1,8)=70.8, p<.0001]$, with the participants responding more rapidly to tactile targets $(M=494 \mathrm{msec})$ than to odor targets ( $M=775 \mathrm{msec}$ ) overall. This difference may partially reflect the fact that it takes about 100 $150 \mathrm{msec}$ for odors presented to the nasal mucosa to permeate through the mucous membrane (Hummel et al., 1996). There was also a main effect of cue validity $[F(1,8)$ $=43.1, p<.0005]$, caused by the participants responding more rapidly on validly cued trials $(M=587 \mathrm{msec})$ than on invalidly cued trials $(M=682 \mathrm{msec})$. Mean cuing effects were numerically larger for tactile targets $(120 \mathrm{msec})$ than for odor stimuli $(71 \mathrm{msec})$, although the interaction between target modality and cue validity was not significant $[F(1,8)=1.8, p=.21] .^{3}$

It is interesting to note that the cuing effects reported here are numerically larger than those reported previously (Spence \& Driver, 1997) when attention was selectively directed to audition, vision (across four experiments, the mean cuing effects for targets in either modality never exceeded $50 \mathrm{msec}$ ), or touch (Spence, Nicholls, \& Driver, in press). However, since these studies used different methodologies, varying in the predictiveness of the cues used, in the amount of practice given, ${ }^{4}$ and in the intertarget intervals used, direct comparison of the magnitude of cuing effects remains an interesting question for further research.

Analysis of the error data revealed no main effects or interactions (all $F \mathrm{~s}<2$ ). Note, though, that the participants made fewer erroneous responses on valid trials than on invalid trials overall, thus allowing us to rule out a speed-accuracy tradeoff account for the RT effects observed (see Spence \& Driver, 1997).

\section{DISCUSSION}

The results clearly show that symbolic visual cues that predict the likely target modality on a trial-by-trial basis can influence discrimination latencies for chemosensory and tactile targets presented in the expected versus unexpected modality, with better performance in the former case. This finding extends the results of numerous previous modality-cuing studies that have demonstrated the facilitatory effects of selectively attending to audition, vision, touch, and nociception (see Spence \& Driver, 1997 , and Spence, Nicholls, \& Driver, in press, for reviews). The present results provide one of the first demonstrations that the processing of chemosensory information can be analyzed using a speeded RT methodology popularized by Posner (e.g., Posner, 1978) to study the effects of attention on information processing in other modalities. All previous studies of the effects of attention on chemosensory information processing have utilized either unspeeded behavioral responses (e.g., Laing \& Glenmarec, 1992) or chemosensory event-related potentials (e.g., Krauel et al., 1998; Pause, Sojka, \& Ferstl, 1997; Pause, Sojka, Krauel, \& Ferstl, 1996).

Our cuing effects cannot reflect a response bias on the part of the participants, because the response dimension 
(left vs. right) was always orthogonal to the cued dimension (odor vs. touch). Hence, instructing the participants to attend to one or the other modality preferentially should not have biased them toward making one response or another (in contrast to many previous studies; see Spence \& Driver, 1997, for a fuller discussion of this issue). We were also able to rule out a criterion-shifting explanation for our results by showing that the participants responded both more rapidly and more accurately to targets in the expected modality than in the unexpected modality (see Duncan, 1980; Spence \& Driver, 1997). Finally, an overt orienting account for these effects on responses to odor is also implausible, because the target stimuli were presented monorhinally to the participants practicing velopharyngeal closure. Hence, any overt changes in the pattern of breathing on expect-odor trials should not have had any impact on the cuing effects observed. Instead, the present results presumably reflect the effects of a purely covert shift of endogenous attention to the chemosensory or tactile modality.

When taken together with similar findings reported for other sensory modalities (e.g., Spence \& Driver, 1997; Spence, Nicholls, \& Driver, in press), the present results support the claim that attention can be selectively directed to a particular sensory modality and that this leads to the preferential processing of stimuli subsequently presented in that modality. These results complement those from other studies showing similar modulatory effects of attention when directed to particular classes of stimuli within a particular sensory modality. For example, Marks and Wheeler (1998) demonstrated that detection thresholds for a particular tastant (e.g., sucrose) were selectively lowered when participants were directing their attention toward that stimulus, relative to when they were expecting another stimulant (e.g., citric acid). Similar results have also been reported within vision (e.g., Wright \& Ward, 1998), audition (e.g., Scharf, 1998), touch (e.g., Spence, Pavani, \& Driver, in press; Whang et al., 1991), nociception (i.e., pain; Miltner, Johnson, Braun, \& Larbig, 1989; Miron et al., 1989), and olfaction (e.g., Laing \& Glenmarec, 1992; Pause et al., 1997; Pause et al., 1996; see also Rabin \& Cain, 1989). Our results are also consistent with those from studies of neurological patients suffering from extinction and neglect, showing that these attentional deficits can affect chemosensory processing (Bellas et al., 1988; Bender \& Feldman, 1952; Mesulam, 1981).

It is important to note that, in the present experiment, as in the majority of previous modality-cuing studies (e.g., Krauel et al., 1998; Miron et al., 1989; see Spence \& Driver, 1997, for a review), stimuli in the different modalities (here, odor and touch) were presented from different spatial locations. It is therefore probable that our cuing effects reflect not only the beneficial effects of selectively attending to a particular sensory modality but also some element of attending to a particular set of spatial locations. That is, the participants may have directed their attention spatially toward the nasal cavity when expecting an odor target and to the regions of space occupied by the hands when expecting a tactile target. Spence and Driver directly assessed the relative contribution of spatial and modality-cuing factors in their study of audiovisual attention, by presenting visual targets from the left or the right in front of the participants and presenting auditory targets either from headphones (spatial confound) or from loudspeakers placed directly behind the target lights (no spatial confound). They found that removing the spatial confound (i.e., auditory and visual stimuli presented from the same set of locations) led to only a small $(11-\mathrm{msec})$, albeit significant, decrease in the size of cuing effects reported. Therefore, given the similarity in design between the present study and that reported by Spence and Driver, it seems likely that spatial cuing factors should have had only a marginal influence on the cuing effects reported here. ${ }^{5}$

Chemosensation involves responses to olfactory, chemical, and painful stimuli and is mediated by the olfactory and trigeminal somatosensory systems (see Cain, 1988). Like many of the odorous substances encountered in everyday life (e.g., Beidler \& Tucker, 1956; Schneider \& Schmidt, 1967; Silver, Mason, Marshall, \& Maruniak, 1986; Stone, Williams, \& Carregal, 1968), the localizable odor target (menthol) used in the present study, activates both the olfactory and the trigeminal submodalities of chemosensation. If, as the weight of empirical evidence now suggests, "pure" odors cannot be lateralized when presented monorhinally (see Cain, 1988, for a review), it would seem most likely that the participants in the present study based their discrimination responses on the trigeminal component of the olfactory stimulus. It remains an interesting question for future research to investigate whether attention can be selectively directed to just the trigeminal or olfactory submodalities of chemosensation or whether attentional effects will spread automatically to the other submodalities of chemosensation.

The neuroanatomical projections of the olfactory and trigeminal systems are certainly different from one another: "Pure" olfactory stimuli, after transduction at the olfactory mucosa, project initially to the olfactory bulb and then on to the secondary and tertiary olfactory cortices of both hemispheres via the olfactory nerve (Kettenmann, Hummel, Stefan, \& Kobal, 1997; Kettenmann et al., 1996); by contrast, irritant chemical components of an "olfactory" stimulus activate the chemospecific small caliber nerve fibers of the trigeminal system innervating the nasal mucosa and project via the ventral posterior medial nucleus of the thalamus to the primary somatosensory cortex of the contralateral hemisphere via the trigeminal or fifth cranial nerve (see Dodd \& Kelly, 1991; though see Hari, Portin, Kettenmann, Jousmäki, \& Kobal, 1997). Given the lack of direct thalamic projections for olfactory stimuli, the present results would seem to suggest that attending to a modality (in particular, olfaction) cannot be achieved solely by thalamic gating (see McCormick \& Bal, 1994).

It is somewhat surprising that the chemosensory modality has remained relatively neglected by cognitive psy- 
chologists interested in attention (a situation that has not changed since the 1920s; see Wells, 1929), given that the central role smell is known to play in modulating behavior in many species (e.g., Axel, 1995). It will be fruitful in future studies to combine the behavioral methods reported here with neuroimaging techniques, such as ERP, PET, or fMRI (see Francis et al., 1999). Furthermore, it would also be interesting to see whether those clinical populations that have been shown to have a selective deficit in shifting their attention between the auditory and visual modalities (see Ciesielski et al., 1995; Godefroy et al., 1996; Hanewinkel \& Ferstl, 1996) also show a similar deficit when attempting to shift their attention to/ from the chemosensory modality (see Seidman et al., 1997).

\section{REFERENCES}

Allport, D. A., Styles, E. A., \& Hsieh, S. (1994). Shifting intentional set: Exploring the dynamic control of tasks. In C. Umiltà \& M. Moscovitch (Eds.). Attention and performance: Conscious and nonconscious information processing (XV, pp. 421-452). Cambridge, MA: MIT Press.

Axel, R. (1995). The molecular logic of smell. Scientific American, 273(4), 130-137.

BeIDLER, L. M., \& TUCKER, D. (1956). Olfactory and trigeminal nerve responses to odors. Federation Procecdings, $15,14$.

BÉKÉsY, G. VON (1964). Olfactory analogue to directional hearing. Journal of Applied Physiology, 19, 369-373.

Bellas, D. N., Novelly, R. A., Eskenazi, B., \& Wasserstein, J. (1988). The nature of unilateral neglect in the olfactory sensory system. Neuropsychologia, 26, 45-52.

Bender, M. B., \& Feldman, D. S. ( 1952). Extinction of taste sensation on double simultaneous stimulation. Neurology, 2, 195-202.

Bushnell, M. C., Duncan, G. H., Dubner, R., \& He, L. F. (1984). Activity of trigeminothalamic neurons in medullary dorsal horn of awake monkeys trained in a thermal discrimination task. Journal of Neurophysiology, 52, 170-187.

Bushnell, M. C., Duncan, G. H., Dubner, R., Jones, R. L., \& MAIXNER, W. (1985). Attentional influences on noxious and innocuous cutaneous heat detection in humans and monkeys. Journal of Neuroscience, 5, 1103-1110.

CaIN, W. S. (1976). Olfaction and the common chemical sense: Some psychophysical contrasts. Sensory Processes, 1, 57-67.

CAIN, W. S. (1988). Olfaction. In R. C. Atkinson, R. J. Herrnstein, G. Lindsey, \& R. D. Luce (Eds.), Stevens' Handbook of experimental psychology: Perception and motivation (pp. 409-459). New York: Wiley.

Ciesielski, K. T., Knight, J. E., Prince, R. J., Harris, R. J., \& HandMAKER, S. D. (1995). Event-related potentials in cross-modal divided attention in autism. Neuropsychologia, 33, 225-246.

DodD, J., \& Kelly, J. P. (1991). Trigeminal system. In E. R. Kandell, J. H. Schwartz, \& T. M. Jessell (Eds.), Principles of neural science (3rd ed., pp. 701-710). Englewood Cliffs, NJ: Prentice-Hall.

DunCAN, J. (1980). The demonstration of capacity limitation. Cognitive Psychology, 12, 75-96.

Francis, S., Rolls, E. T., Bowtell, R., McGlone, F., O'Doherty, J., Browning, A., Clare, S., \& Smith, E. (1999). The representation of pleasant touch in the brain and its relationship with taste and olfactory areas. NeuroReport, 10, 453-459.

Frith, C. D., \& Friston, K. J. (1996). The role of the thalamus in "top down" modulation of attention to sound. Neurolmage, 4, 210-215.

Godefroy, O., Lhullier, C., \& Rousseaux, M. (1996). Non-spatial attention disorders in patients with frontal or posterior brain damage. Brain, 119, 191-202.

Hanewinkel, R., \& FERSTL, R. (1996). Effects of modality shift and motor response shift on simple reaction time in schizophrenia patients. Journal of Abnormal Psychology, 105, 459-463.
Harı, R., Portin, K., Kettenmann, B., Jousmäkı, V., \& Kobal, G. (1997). Right-hemisphere preponderance of responses to painful $\mathrm{CO}_{2}$ stimulation of the human nasal mucosa. Pain, 72, 145-151.

Hayes, R. L., Price, D. D., Ruda, M. A., \& Dubner, R. (1981). Neuronal activity in medullary dorsal horn of awake monkeys trained in a thermal discrimination task: II. Behavioural modulation of responses to thermal and mechanical stimuli. Journal of Neurophysiology, 46, 428-443.

HiRSCH, A. (1862). Expériences chronoscopiques sur la vitesse des différentes sensations et de la transmission nerveuse [Chronoscopic experiments on the speed of different senses and nerve transmission]. Bulletin de la Société des Sciences de Neuchâtel, 6, 100-114.

Hsiao, S. S., O'Shaughnessy, D. M., \& Johnson, K. O. (1993). Effects of selective attention on spatial form processing in monkey primary and secondary somatosensory cortex. Journal of Neurophysiology. 70, 444-447.

hummel, T., KneCht, M., \& Kobal, G. (1996). Peripherally obtained electrophysiological responses to olfactory stimulation in man: Electroolfactograms exhibit a smaller degree of desensitization compared with subjective intensity estimates. Brain Research, 717, 160-164.

Hummel. T., \& Kobal, G. (1999). Chemosensory event-related potentials to trigeminal stimuli change in relation to the interval between repetitive stimulation of the nasal mucosa. European Archives of Otorhinolaryngology, 256, 16-21.

Kettenmann, B., Hummel, C., Stefan, H., \& Kobal. G. (1997). Multiple olfactory activity in the human neocortex identified by magnetic source imaging. Chemical Senses, 22, 493-502.

Kettenmann, B., Jousmäki, V., Portin, K., Salmelin, R., Kobal, G., \& HARI, R. (1996). Odorants activate the human superior temporal sulcus. Neuroscience Letters, 203, 143-145.

Kobal, G. (1985). Pain-related electrical potentials of the human nasal mucosa elicited by chemical stimulation. Pain, 22, 151-163.

Kobal, G.. \& Hummel. T. (1991). Human electro-olfactograms and brain responses to olfactory stimulation. In D. G. Laing, R. L. Doty, \& W. Breipohl (Eds.), The human sense of smell (pp. 199-215). Berlin: Springer-Verlag.

Kobal, G.. Hummel, T., \& Van Toller, S. (1992). Differences in human chemosensory evoked potentials to olfactory and somatosensory chemical stimuli presented to left and right nostrils. Chemical Senses, 17, 233-244.

Kobal, G., Van Toller, S., \& Hummel, T. (1989). Is there directional smelling? Experimentia, 45, 130-132.

Krauel, K., Pause. B. M., Solka, B.. SChott, P., \& Fersti, R. (1998). Attentional modulation of central odor processing. Chemical Senses, 23, $423-432$.

Laing. D. G., \& Glenmarec, A. (1992). Selective attention and the perceptual analysis of odor mixtures. Physiology \& Behaviour, 52. $1047-1053$.

Marks, L. E. \& WheEler. M. E. (1998). Attention and the detectability of weak taste stimuli. Chemical Senses, 23, 19-29.

McCaul, K. D., \& Haugtvedt, C. (1982). Attention, distraction, and cold-pressor pain. Journal of Personality \& Social Psychology, 43. 154-162.

McCaul, K. D., \& Malott, J. M. (1984). Distraction and coping with pain. Psychological Bulletin, 95, 516-533.

MCCORMick. D. A., \& BAL, T. (1994). Sensory gating mechanisms of the thalamus. Current Opinion in Neurobiologv, 4, 550-556.

Mesulam, M. (1981). A cortical network for directed attention and unilateral neglect. Annals of Neurology, 10, 309-325.

MiLLER, J. O. (1988). A warning about median reaction time. Journal of Experimental Psychology: Human Perception \& Performance, 14. 539-543.

Miltner, W., Johnson, R., JR., Braun, C., \& Larbig, W. (1989). Somatosensory event-related potentials to painful and non-painful stimuli: Effects of attention. Pain, 38, 303-312.

Miron, D., Duncan, G. H., \& Bushnel.l, M. C. (1989). Effects of attention on the intensity and unpleasantness of thermal pain. Pain, 39. 345-352.

NiCOLAS, S. (1997). On the speed of different senses and nerve transmission by Hirsch (1862). Psychological Research, 59, 261-268. 
Pause, B. M., Sojka, B., \& Ferstl, R. (1997). Central processing of odor concentration is a temporal phenomenon as revealed by chemosensory event-related potentials (CSERP). Chemical Senses, 22, 9-26.

Pause, B. M., Sojka, B., Krauel, K., \& Ferstl, R. (1996). The nature of the late positive complex within the olfactory event-related potential. Psychophvsiologv, 33, 376-384.

PoSNER, M. I. (1978). Chronometric explorations of mind. Hillsdale, $\mathrm{NJ}$ : Erlbaum.

Price, J. L. (1990). Olfactory system. In G. Paxinos (Ed.), The human nervous system (pp. 979-998). San Diego: Academic Press.

RABIN, M. D., \& CAIN, W. S. (1989). Attention and learning in the perception of odor mixtures. In D. G. Laing, W. S. Cain, R. L. McBride, \& B. W. Ache (Eds.), Perception of complex smells and tastes (pp. 173 188). Sydney: Academic Press.

Rogers, R. D., \& Monseli., S. (1995). Costs of a predictable switch between simple cognitive tasks. Journal of Experimental Psychology: General, 124, 207-231.

SCHARF, B. (1998). Auditory attention: The psychoacoustical approach. In H. Pashler (Ed.), Attention (pp. 75-117). London: Psychology Press.

SC HNEIDER, R. A., \& SCHMIDT, C. E. (1967). Dependency of olfactory localization on non-olfactory cues. Physiology \& Behaviour, 2 . 305-309.

Seidman. L. J., Goldstein, J. M., Goodman, J. M., Koren. D., Turner, W. M., Faraone, S. V., \& Tsuang, M. T. (1997). Sex differences in olfactory identification and Wisconsin card sorting performance in schizophrenia: Relationship to attention and verbal ability. Biological Psychiatry, 42, 104-115.

Silver, W. L., Mason, J. R.. Marshai.l. D. A.. \& Maruniak. J. A. (1986). Rat trigeminal, olfactory, and taste responses after capsaicin desensitization. Brain Research, 333, 45-54.

Skrami.ık, E. voN (1925). Über die Lokalisation der Empfindungen bei den niederen Sinnen [On the localization of sensation in the lower senses]. Zeitschrift für Sinnesphrsiologie, 56, 69-140.

SPENCE, C., \& Driver. J. (1997). On measuring selective attention to an expected sensory modality. Perception \& Psichophrsics, 59, 389-403.

Spence. C., Nic holl.s. M. E. R.. \& Driver, J. (in press). The cost of expecting events in the wrong sensory modality. Perception \& Psychophisics.

Spence, C.. Pavani, F., \& Driver, J. (in press). Crossmodal links in spatial attention between vision and touch: Allocentric coding revealed by crossing the hands. Journal of Experimental Psychology: Human Perception \& Performance.

Stone, H., Will.iams, B., \& Carrf.gal., J. A. (1968). The role of the trigeminal nerve in olfaction. Experimental Neurology, 21, 11-19.

VAN Toller, C., Kirk-Smith, M. Si.fight, D., WoOd, N., \& LomBARD. J. (1980). Hemispheric processing of odours. Biological Psychologv, 11, 262.

WELLS, F. L. (1929). Reaction times to affects accompanying smell stimuli. American Journal of Psvchology, 41, 83-86.

Whang, K. C., Burton. H., \& Shulman, G. L. (1991). Selective attention in vibrotactile tasks: Detecting the presence and absence of amplitude change. Perception \& Psychophysics, 50, 157-165.

WRIGHT, R. D., \& WARD. L. M. (1998). The control of visual attention. In R. D. Wright (Ed.), Visual attention (pp. 132-186). New York: Oxford University Press.
WUndT, W. (1893). Grundzüge der physiologischen Psychologie [Foundations of physiological psychology] (4th ed.). Leipzig: Wilhelm Engelmann.

Zucco, G. M., \& Tressotd, P. E. (1988). Hemispheric differences in odour recognition. Cortex, 25, 607-615.

\section{NOTES}

1. Note that the poor localizability of olfactory stimuli, together with the lack of direct collicular projections, means that mechanisms of spatial attention are also likely to be lacking in the olfactory system. This contrasts with the other modalities (i.e., audition, vision, and touch), which all have strong collicular connections and show robust spatial attentional effects.

2 . We are aware of only one previous study that has attempted to use a speeded responding methodology to investigate chemosensory information processing (Zucco \& Tressoldi, 1988), and this was not concerned with the effects of attention.

3. We conducted a further analysis of the RT data, with the additional between-subjects factor of naivety to look for any potential differences between naive and nonnaive participants. This analysis revealed no main effect of naivety, and no interaction between naivety and any of the other terms (all $F \mathrm{~s}<1$ ). However, the mean cuing effects were marginally smaller for nonnaive participants $(66$ and $115 \mathrm{msec}$ for odor and tactile targets, respectively) than for the naive group overall (mean cuing effects of 76 and $125 \mathrm{msec}$, respectively). However, analysis of the data from just the 5 naive participants revealed that these mean cuing effects were still significant when analyzed by themselves $(p s<.05$ and 01 , respectively).

4. In order to investigate any effects of practice on modality-cuing effects, we conducted an additional analysis, with the extra factor of practice (Trials $1-48$ vs. Trials $49-96$ ). This revealed that RTs for invalidly cued ol factory targets were significantly slower in the first block than in the second block (no such effect was reported for the other conditions), leading to a three-way interaction between practice, target modality, and cue validity $[F(1,8)=6.2, p<.05]$ and to near-significant effects of practice $[F(1,8)=3.8, p=.09]$ and of practice $\times$ target modality $[F(1,8)=4.7, p=.07]$. It is interesting to note that mean cuing effects for targets in both modalities were numerically larger in the second block ( $M \mathrm{~s}=79$ and $96 \mathrm{msec}$ for visual targets and olfactory targets, respectively) than in the first block $(M \mathrm{~s}=60$ and $42 \mathrm{msec}$, respectively), suggesting that the participants became better able to focus their attention on a particular modality as the experiment progressed.

5. To remove this potential spatial confound, tactile and olfactory stimuli should be presented from exactly the same spatial locations (i.e., olfactory and tactile stimuli both presented to the left or the right nostril). In this way, a cue to the likely target modality gives no indication of the likely target location. However, when we tried to do this in preliminary studies, the vibrotactile stimuli were clearly audible when placed so close to the participant's ears.

(Manuscript received May 18, 1999; revision accepted for publication September 2, 1999.) 